\title{
FEMAN: Fuzzy-Based Energy Management System for Green Houses Using Hybrid Grid Solar Power
}

\author{
Abdellah Chehri and Hussein T. Mouftah \\ School of Electrical Engineering and Computer Science, University of Ottawa, 800 King Edward Avenue, \\ Ottawa, ON, Canada K1N 6N5 \\ Correspondence should be addressed to Abdellah Chehri; achehri@uottawa.ca
}

Received 3 March 2013; Accepted 19 June 2013

Academic Editor: Zuhal Oktay

Copyright (C) 2013 A. Chehri and H. T. Mouftah. This is an open access article distributed under the Creative Commons Attribution License, which permits unrestricted use, distribution, and reproduction in any medium, provided the original work is properly cited.

The United Nations has designated the year 2012 as the international year of sustainable energy. Today, we are seeing a rise in global awareness of energy consumption and environmental problems. Many nations have launched different programs to reduce the energy consumption in residential and commercial buildings to seek lower-carbon energy solutions. We are talking about the future green and smart houses. The subject of smart/green houses is not one of "why," but rather "how," specifically: "how making the future house more energy efficient." The use of the renewable energy, the technology and the services could help us to answer this question. Intelligent home energy management is an approach to build centralized systems that deliver application functionality as services to end-consumer applications. The objective of this work is to develop a smart and robust controller for house energy consumption with maximizing the use of solar energy and reducing the impact on the power grid while satisfying the energy demand of house appliances. We proposed a fuzzy-based energy management controller in order to reduce the consumed energy of the building while respecting a fixed comfort.

\section{Introduction}

The depletion of nonrenewable resource fuels such as gas, coal and petroleum on one hand, and the global climate change and awareness of the impact of harmful emissions on health and the environment on the other hand have led to an increased interest in the way we are using the energy [1].

Renewable energy is energy that comes from resources which are continually replenished such as sunlight, wind, rain, tides, waves, biomass, and geothermal heat. Nowadays there exist a wide range of technologies which possess this capability.

However, most energy and environmental gains can be achieved by focusing efforts on improving the energy efficiency in residential and commercial buildings. Data collected by the Energy Information Administration shows that buildings account for $37 \%$ of the energy used in the United States, and of that energy, $53 \%$ is consumed by residential buildings [2].

In the short term, the energy conservation will certainly become the most important issue to address amongst engineers, researchers, and environmentalists with the rising consumption of resources and deterioration of the environment.

Conserving energy would reduce the rise in energy costs and can reduce the need for new power plants. The reduced energy demand can provide more flexibility in choosing a cleaner and efficient method of energy production. Reduction in the emissions would certainly cause less hazard to the environment. In other terms, energy conservation is often the most economical solution to energy shortages and is more environmentally friendly [3].

Considering the large energy consumption of the residential building sector, efforts to decrease energy use and negative environmental impact are an important national and international issue.

The residential sector should play a major role in bringing new energy efficient technologies to the forefront. To further emphasize the importance of creating more energy conscious housing.

However, with populations increasing along with the urbanization of cities, cities have become the main culprits of poorly managed natural resource consumptions. 
The energy efficiency of appliances, lighting, heating, ventilation, and air conditioning (HVAC), and building materials must continue to improve. Unfortunately, the homeowners are often unaware of the technology and materials available or have negative impressions of the cost or ease of installation. Both of these concerns must be addressed for a positive impact in residential buildings to be achieved [4].

The objective of this work is to develop a smart and robust controller for house energy consumption with maximizing the use of solar energy and reducing the impact on the power grid while satisfying the energy demand of house appliances. In addition, the proposed energy management controller is based on user behavior, time-of-use rates, the off-peak and on-peak electricity prices, intelligent control of appliances, and local energy production, and conservation is proposed.

The remainder of this paper is organized as follows. Section 2 deals with the concept of hybrid renewable energy system. Section 3 gives an overview of the solar benefits to Canada energy. Section 4 gives a detail about fuzzy-based energy management system (EMS) for a smart house.

The numerical evaluations using a typical smart house as well as realistic home's amenities and services to confirm our analysis are given in Section 5. Section 6 concludes the paper with some direction for future works.

\section{Moving towards Hybrid Renewable Energy Systems}

The worldwide rise in energy demand accompanied by the rise in prices of petroleum products has led to a profound change in the present day energy infrastructure. The actual electric power infrastructure in most of the developed countries is running near capacity.

There is increasing consent among governmental policy, business leaders, and other key electric grid stakeholders to develop a technologically enhanced electric grid. In the near term, the most promising marriage of the electric grid and new information and communications technology will yield the concept of the smart grid.

The smart grid can be defined as an intelligent grid having the capacity to be extremely efficient and deliver energy at an affordable cost in the decade of high inflation [5].

Nowadays, either industry, government policy, or in academia has identified the following aspects that need to be considered when designing a future electric grid.

(i) Electric power causes approximately 25\% of global greenhouse gas emissions, and utilities are evaluating the need for a more green electric system.

(ii) Renewable and distributed power generation will play a more prominent role in reducing greenhouse gas emissions.

(iii) Real-time monitoring of grid performance (e.g., agents deployed along the electric line) will help identify the concerns over grid reliability thereby increasing grid reliability and utilization, reducing blackouts, and increasing financial returns on investments in the grid.

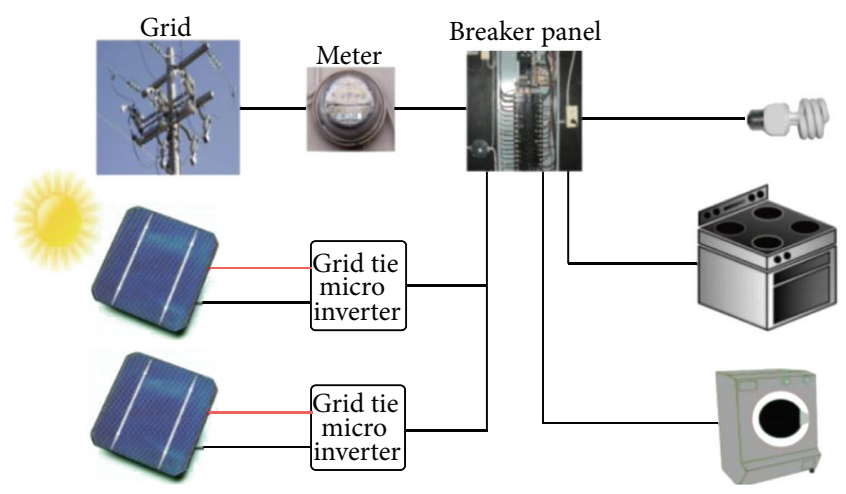

Figure 1: A diagram of the power system using electrical grid and solar power.

One of the important applications of smart grid is that it encourages home and business owners to invest in microgeneration technologies in order to supply some of their own energy and reduce the demand on the electric grid.

Among the various renewable energy resources, the most popular sources are the solar and wind energy. These energies are nonexhaustive, site dependent, and green. Microgeneration models consist of various sources of energy such as wind turbines, photovoltaic (PV) panels, and fuel cells, and so forth [6]. The combination of these energy sources in different patterns results in multiple designs of hybrid renewable energy systems (HRES) [7].

The hybrid renewable energy systems can be generalized as a system that utilizes electric power from both conventional grid as well as from the renewable sources [8].

Compared to the actual electrical grid, the HRES could reduce dramatically the fuel consumption. Also, the HRES could decrease the consumer electricity bills through the use of energy efficient appliances and by monitoring the time of consumption of electricity.

Last but not least, the HRES can reduce $\mathrm{CO}_{2}$ emissions through efficient generation and minimizing thermal generation. As a result, HRES could make the system cost-effective, green, and highly reliable in terms of producing power $[9,10]$.

\section{Solar Power in Canada}

Solar power is one of the fastest growing renewable energy technologies, and it is expected that it will play a major role in the future global electricity generation mix. Solar PV systems are also one of the most "democratic" renewable technologies, in that their modular size means that they are within the reach of individuals, cooperatives, and small businesses who want to access their own generation and lock-in electricity prices.

The smart house includes an off-grid solar power system, where the solar array was sized to produce $100 \%$ of the energy required to run the home year round. The system is called "off-grid" because it is not intended to be connected to the nation's electrical grid.

A diagram of the power system can be seen in Figure 1. The system consists of a quantity of photovoltaic modules that provide power to a battery charge controller. The charge 


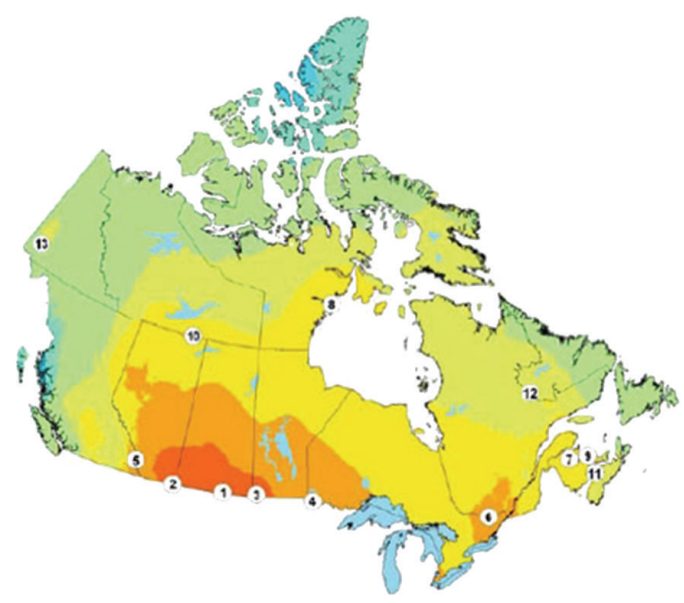

\begin{tabular}{|c|c|c|c|c|c|c|c|c|c|c|}
\hline \multicolumn{3}{|c|}{ KWh/KW } & \multicolumn{3}{|c|}{ PV potential } & & & & & \\
\hline & & & & & & & & & & \\
\hline $\begin{array}{l}8 \\
\stackrel{0}{10} \\
\vee\end{array}$ & $\begin{array}{l}8 \\
80 \\
1 \\
0 \\
0 \\
0\end{array}$ & $\begin{array}{l}8 \\
8 \\
1 \\
8 \\
8\end{array}$ & \begin{tabular}{l}
8 \\
$\infty$ \\
1 \\
$\wp$ \\
\hdashline
\end{tabular} & $\begin{array}{l}8 \\
\circ \\
1 \\
\text { 1 } \\
8\end{array}$ & $\begin{array}{l}8 \\
8 \\
1 \\
8 \\
8\end{array}$ & $\begin{array}{l}8 \\
0 \\
7 \\
8 \\
8 \\
8\end{array}$ & $\begin{array}{l}8 \\
\stackrel{1}{1} \\
1 \\
8 \\
8 \\
-1\end{array}$ & 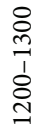 & $\begin{array}{l}8 \\
\stackrel{+}{1} \\
1 \\
8 \\
8 \\
-1\end{array}$ & $\begin{array}{l}+ \\
\text { ○ } \\
\text { 品 }\end{array}$ \\
\hline
\end{tabular}

Figure 2: The potential of solar energy in Canada (Natural Resources Canada).

controller regulates the voltage to safely charge a set of batteries. An inverter that simulates electrical grid quality power is connected to the batteries to provide alternating current power to the house.

A study performed at natural resource Canada makes the case that a large amount of solar energy across the country could be exploited. The graphics below indicate the phenomenal potential of the Canadian solar industry. Considering that the surface area typical house roof $\left(12-15 \mathrm{~m}^{2}\right)$ is covered with PV panels with $25 \%$ conversion efficiency, 5 to $7 \mathrm{kWh}$ of electrical energy can be produced.

Canada's use of solar energy has increased in recent years, although it remains relatively small in terms of market penetration. Installed capacity for solar thermal power has seen average annual growth of $9.5 \%$ since 2000 , reaching a capacity of 819 megawatts of thermal power in 2011. The 2008-2011 period was marked by the exponential growth of installed capacity for solar photovoltaic power, with the annual growth rate of $147.3 \%$. In 2011, the installed capacity reached 495 megawatts.

However, the solar panel only produces energy while the sun is shining. If electricity is desired at other times, some sort of storage is needed. Most solar electric systems use batteries to store the energy from the solar panels.

The advantage with such technologies is that they are small, cost-effective, and reliable compared to traditional large power plants. For our system, we assume that the backup solar batteries are able to store $6 \mathrm{kWh}$ (see Figure 2).

\section{Fuzzy-Based Energy Management System (EMS) for a Smart House}

Houses are becoming smarter in that their ability to reduce energy usage is increasing. Traditional stand-alone, complex systems that manage various appliances are now converging towards a common wireless wireline infrastructure that allows these devices to communicate with each other and coordinate their actions which can reduce the consumed power. The smart home is modeled in discrete time. Hence, all electrical quantities are modeled as energy blocks [11].

As discussed earlier, the objective of this work is to develop a stable, robust, and optimal switching supervisory controller for the smart house that will maximize the use of solar energy and reduce the impact on the power grid while satisfying the energy demand of smart house appliances [12].

The energy management problem is defined as a load side demand management problem where the charging demand is controlled to optimize the operation of the grid. The power split on the source side is managed by a simple rule such that the PV panels get first priority and supply maximum possible power [13]. The remaining demand is supplied through the grid.

The objective of the energy management controller is to control the charging power of the consumed energy such that the grid power utilization is minimized particularly during the peak period.

In continuous time, the optimal control problem is

$$
P_{\text {ap }}(n, t)=\operatorname{argmin} \int f\left(P_{\text {grid }}(t)\right) d t,
$$

with power and energy balance equations

$$
\begin{aligned}
P_{\text {grid }}(t) & =\sum_{n=1}^{N} P_{\text {ap }}(n, t)-P_{\text {solar }}(t)-P_{\text {bu }}(t) \\
\int_{\text {day }}( & \left.P_{\text {solar }}(t)+P_{\text {grid }}(t)+P_{\text {bu }}(t)\right) d t \\
& -\int_{d} \sum_{n=1}^{N} P_{\text {ap }}(n, t)=0 .
\end{aligned}
$$

In the above, $P_{\text {solar }}(t)$ is the solar power, $P_{\text {grid }}(t)$ is the grid power, and $P_{\mathrm{bu}}(t)$ is the power of the batteries (i.e., backup systems). These batteries could be charged by the solar system or by grid during the peak-off time. The $P_{\text {ap }}(t)$ is the consumed power from the house appliances.

The main problem now is to find time to switch from PV to grid and from the grid to PV and vice versa. The switching point should take into consideration the available power at $P_{\mathrm{bu}}(t)$, the user behavior, time-of-use rates, and the off-peak and on-peak electricity prices.

In his work we proposed a smart house energy management based on Mamdani's fuzzy inference system. It was designed to reduce costs for the householder. Figure 3 illustrates the framework of the fuzzy-based inference system for energy management system.

As shown in Figure 3, smart meter connects the traditional grid, energy storage unit (or backup system), and the other house appliances. Smart meter receives power information from distribution grid which contains power price and grid load. The integrated fuzzy-based EMS will 


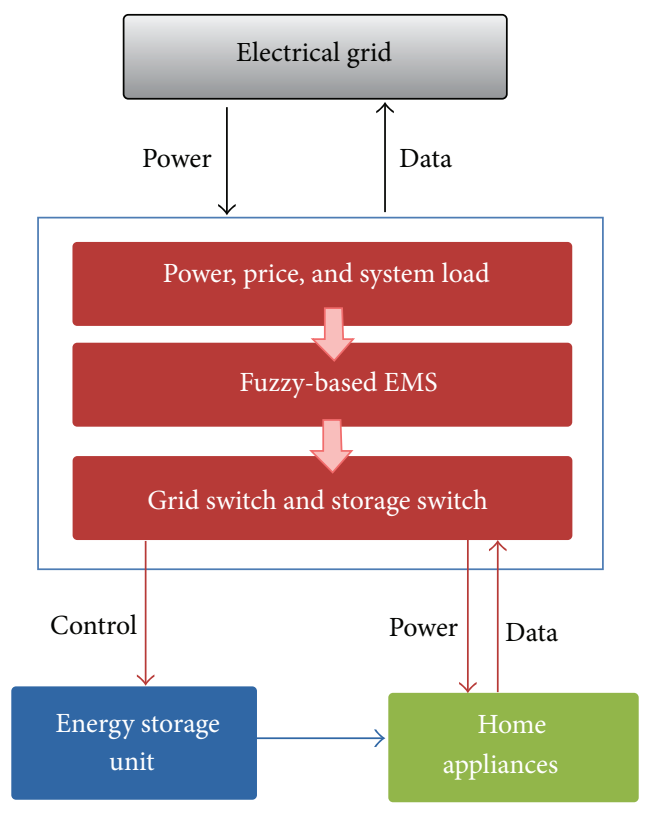

FIGURE 3: Fuzzy-based inference system for energy management system.

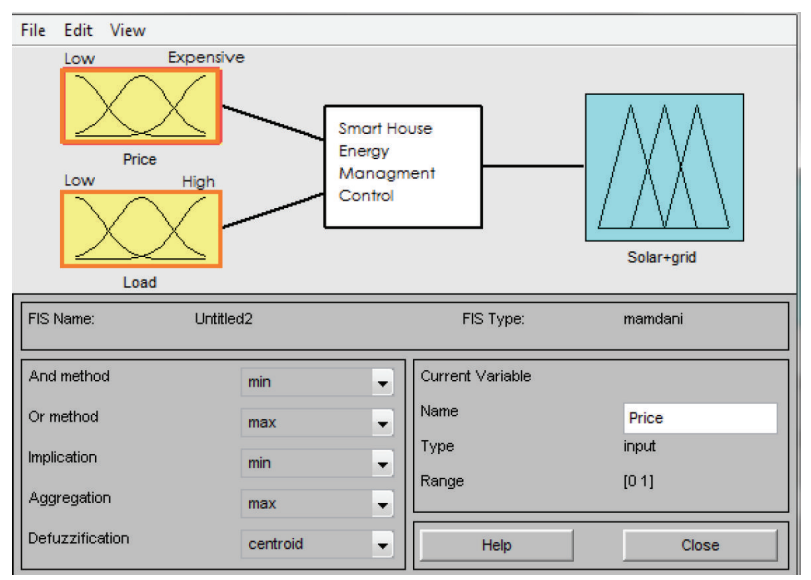

FIGURE 4: Rules of proposed mamdani’s fuzzy inference system.

process the input of price and load and generate output which will be sent as a control signal to operate grid switch and storage switch.

The control signal sent to grid switch will determine how smart meter directs electricity from the distribution grid to energy storage unit and other household appliances. The control signal sent to storage switch will operate the energy storage unit and it will decide whether an energy storage unit is charging or releasing.

Figure 4 illustrates the rules of Mamdani's Fuzzy Inference System. The system is composed of two inputs. As shown in this figure, input 1 represents the electricity price (low, medium, and expensive) and input 2 is backup unit load (low, medium, and high). Output is the signal that controls energy storage unit. Fur rules represent the knowledge base
TABLE 1: Typical household electricity consumption pattern.

\begin{tabular}{|c|c|c|c|}
\hline Appliance & $\begin{array}{c}\text { Power } \\
\text { consumption } \\
\text { (watts) }\end{array}$ & Usage per day & $\begin{array}{c}\text { Daily power } \\
\text { consumption } \\
(\mathrm{W} / \mathrm{h})\end{array}$ \\
\hline \multicolumn{4}{|l|}{ Refrigerator } \\
\hline Refrigerator & 45 & 24 hours & 1080 \\
\hline Freezer & 52 & 24 hours & 1248 \\
\hline \multicolumn{4}{|l|}{ Cooking } \\
\hline Electric range & 365 & 4 hours & 1460 \\
\hline Microwave & 60 & $10 \mathrm{~min}$ & 10 \\
\hline Coffee maker & 30 & $10 \mathrm{~min}$ & 3 \\
\hline Toaster oven & 50 & $10 \mathrm{~min}$ & 5 \\
\hline \multicolumn{4}{|l|}{ Laundry } \\
\hline Dryer & 1500 & 1 hour & 1500 \\
\hline Washer & 500 & 1 hour & 500 \\
\hline Iron & 50 & $10 \mathrm{~min}$ & 300 \\
\hline \multicolumn{4}{|l|}{ Entertainment } \\
\hline Color TV & 100 & 5 hours & 500 \\
\hline Stereo & 100 & 3 hours & 300 \\
\hline Computer & 60 & 3 hours & 180 \\
\hline \multicolumn{4}{|l|}{ Heating } \\
\hline Water heating & 180 & 20 hours & 3600 \\
\hline HVCS & 250 & 24 hours & 6000 \\
\hline \multicolumn{4}{|l|}{ Other } \\
\hline Lighting & 300 & 6 hours & 1800 \\
\hline Cell charging & 8 & 4 hours & 32 \\
\hline Car block heater & 200 & 2 hours & 400 \\
\hline
\end{tabular}

which determines how FIS works. These rules are based on consideration of cost reduction for the householder.

Trend 1: When power price is cheaper, the backup system is charging more.

Trend 2: When power price is more expensive, the backup system is releasing more.

Trend 3: When PV is higher, the backup system is charging more.

Trend 4: When PV is lower, the backup system is releasing more.

The backup power system will be used mainly when the electricity price is expensive and when the solar system is not available (during the night or cloudy day).

\section{System Evaluation}

The daily electrical requirements were estimated for the house. This estimate required the specification of all of the appliances that would be used in the house. The results of the electrical use estimation typical Canadian house are shown in Table 1.

As seen in Figure 5(a), there exists three time period(s) during the day characterizing peak demand of electricity. Figure 5(b) shows the hourly power price curve of a typical day (Ottawa hydro). The highest hourly price is from 7 to 


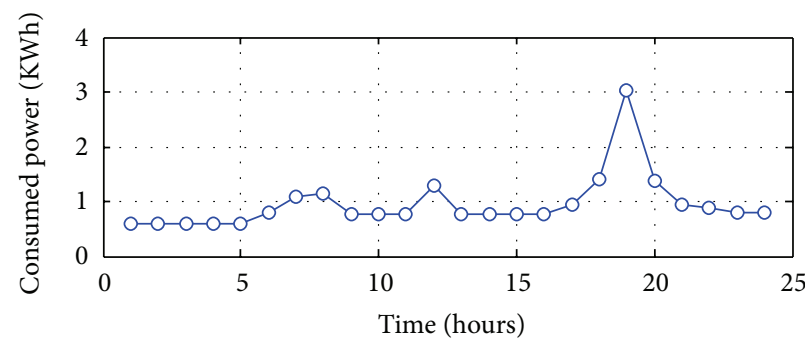

(a)

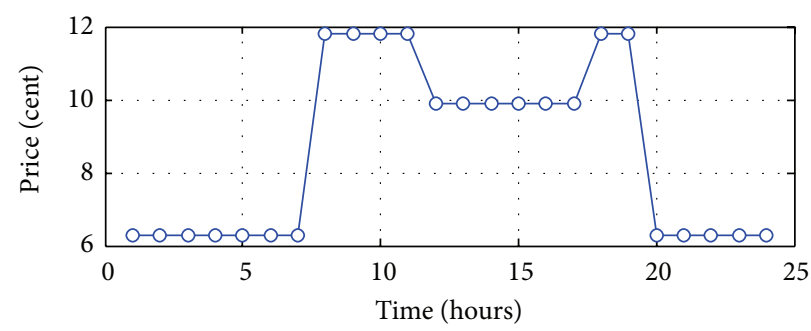

(b)

FIGURE 5: (a) Typical household electricity consumption pattern. (b) Typical hourly power price [14].

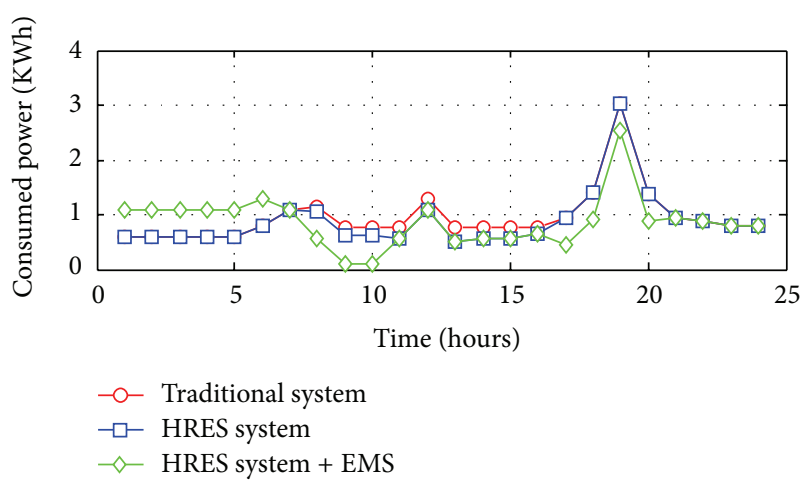

(a)

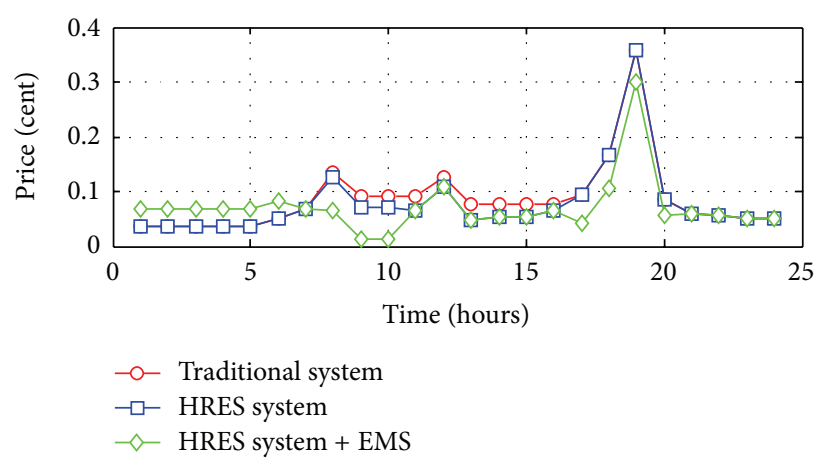

(b)

Figure 6: (a) Load curve for the three systems. (b) Hourly cost curve of three systems.

$11 \mathrm{~h}$ and from 17:00 to 19:00. The curves show the on-peak (when demand for electricity is the highest); mid-peak (when demand for electricity is moderate); and off-peak (when demand for electricity is the lowest).

The size of the solar array required for a given load and level of sun hours can be calculated with (3). The calculations show that the minimum size for the installation is $316.5 \mathrm{~W}$

$$
\begin{aligned}
\operatorname{Load}(\mathrm{Wh} / \text { day }) & =316 \mathrm{~W} * 5 \mathrm{~h} / \text { day } \\
& =1580 \mathrm{Wh} / \text { day. }
\end{aligned}
$$

Figure 6(a) shows the load curve of household without using the PV power or only when the house use the distributed grid (red line), then when the house is equipped with a PV system but without EMS control (blue line), and finally when the house is equipped with both PV and fuzzy-based EMS control (green line).

Figure 6(b) shows the hourly cost of power consumption of the three configurations.

The proposed fuzzy based EMS approach usually resulted in cost saving better than the predicted traditional and HRES system.

Based on these results we could estimate the monthly electricity bill for the three systems. While the bill is about 62.05 CAN \$ for the traditional system, this value decreases to 56.68 CAN \$ for the HRES-PV system. However, the householder could decrease more his bill if the system uses an EMR controller (49.02 CAN \$). This saving represented around of $20 \%$ of the initial bill.

\section{Conclusion}

The concept of smart home energy management involves the integration of various appliances with a smart control unit capable of bidirectional wireline or wireless communication between the controller and the utility. One problem that arises with these features is various compatibility issues between the different appliances, various smart controllers, and communication protocols.

In this paper we have developed a smart energy control for house energy consumption with maximizing the use of solar energy and reducing the impact on the power grid while satisfying the energy demand of house appliances. We proposed a fuzzy-based energy management control in order to reduce the consumed energy of the building while respecting a fixed comfort.

The results demonstrated that the proposed EMS controller provides a better strategy compared to the conventional method for cost saving (almost 20\%).

\section{References}

[1] J. Byun, I. Hong, B. Kang, and S. Park, "A smart energy distribution and management system for renewable energy distribution and context-aware services based on user patterns and load forecasting," IEEE Transactions on Consumer Electronics, vol. 57, no. 2, pp. 436-444, 2011.

[2] U.S. Department of Energy, The Smart Grid: An Introduction, 2008, http://www.oe.energy.gov/SmartGridIntroduction.htm. 
[3] A. Chehri and H. T. Mouftah, "A service-oriented architecture for smart building energy management," in Proceedings of the of IEEE International Conference on Communications (ICC '13), Budapest, Hungary, June 2013.

[4] M. Chan, D. Estève, C. Escriba, and E. Campo, "A review of smart homes-present state and future challenges," Computer Methods and Programs in Biomedicine, vol. 91, no. 1, pp. 55-81, 2008.

[5] Y. Chen and L. Wang, "A power market model with renewable portfolio standards, green pricing and GHG emissions trading programs," in Proceedings of the IEEE Energy 2030 Conference, ENERGY, pp. 1-7, November 2008.

[6] R. Sioshansi and P. Denholm, "The value of concentrating solar power and thermal energy storage," IEEE Transactions on Sustainable Energy, vol. 1, no. 3, pp. 173-183, 2010.

[7] A. Hajizadeh and M. A. Golkar, "Intelligent power management strategy of hybrid distributed generation system," International Journal of Electrical Power and Energy Systems, vol. 29, no. 10, pp. 783-795, 2007.

[8] US Department of Energy, "Building energy data book 2010," Tech. Rep., US Department of Energy, Office of Energy Efficiency and Renewable Energy, 2011.

[9] K. Ehrhardt-martinez and K. A. Donnelly, "Advanced Metering Initiatives and Residential Feedback Programs: A Meta-Review for Household Electricity-Saving Opportunities," Energy, 2010.

[10] A.-L. Lindén, A. Carlsson-Kanyama, and B. Eriksson, "Efficient and inefficient aspects of residential energy behaviour: what are the policy instruments for change?" Energy Policy, vol. 34, no. 14, pp. 1918-1927, 2006.

[11] L. G. Swan and V. I. Ugursal, "Modeling of end-use energy consumption in the residential sector: a review of modeling techniques," Renewable and Sustainable Energy Reviews, vol. 13, no. 8, pp. 1819-1835, 2009.

[12] A. Pina, C. Silva, and P. Ferrão, "The impact of demand side management strategies in the penetration of renewable electricity," Energy, vol. 41, no. 1, pp. 128-137, 2012.

[13] B. Sütterlin, T. A. Brunner, and M. Siegrist, "Who puts the most energy into energy conservation? A segmentation of energy consumers based on energy-related behavioral characteristics," Energy Policy, vol. 39, no. 12, pp. 8137-8152, 2011.

[14] http://www.hydroottawa.com/. 


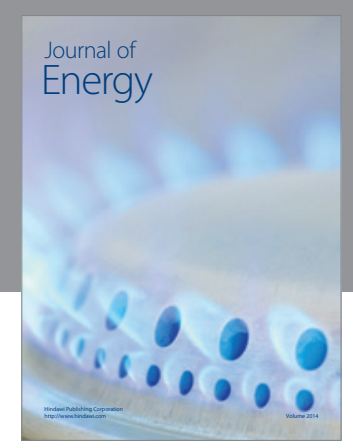

Journal of

Industrial Engineering
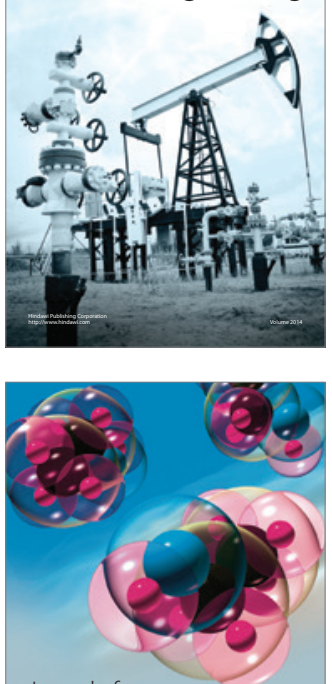

Fuels
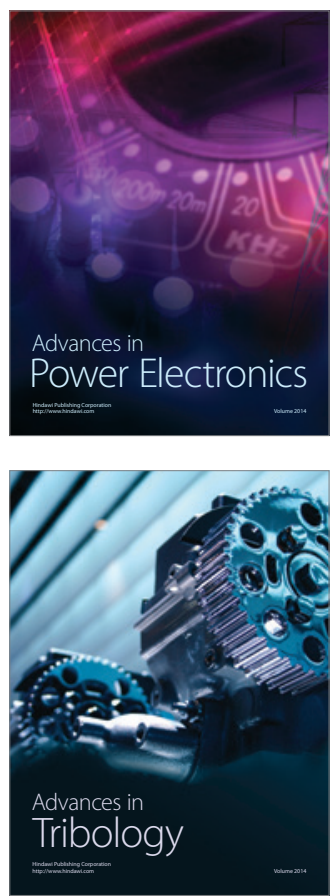

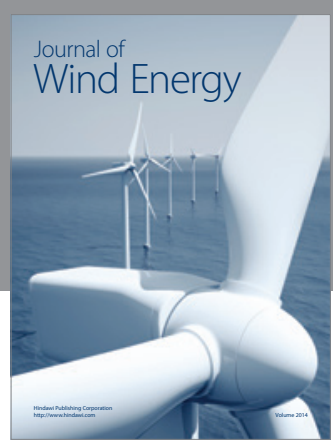

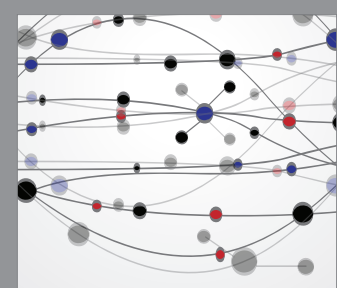

The Scientific World Journal

Submit your manuscripts at http://www.hindawi.com

Journal of

Structures
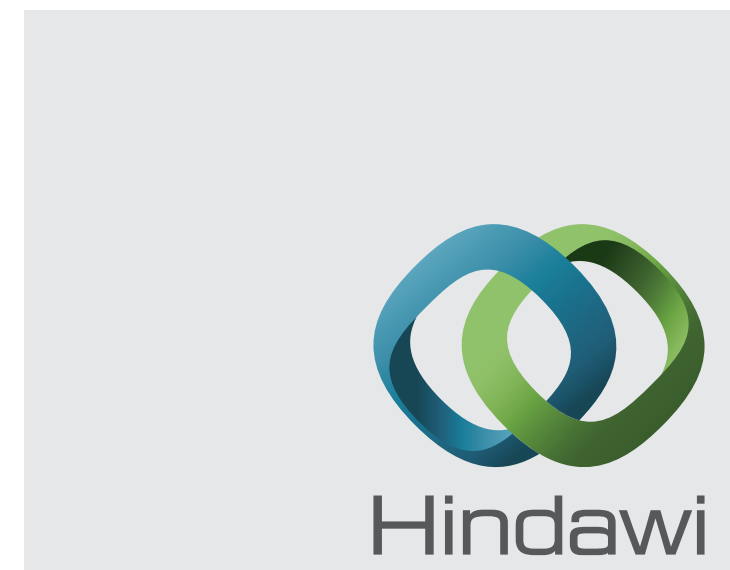

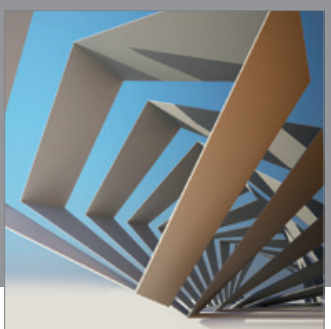

Rotating

Machinery
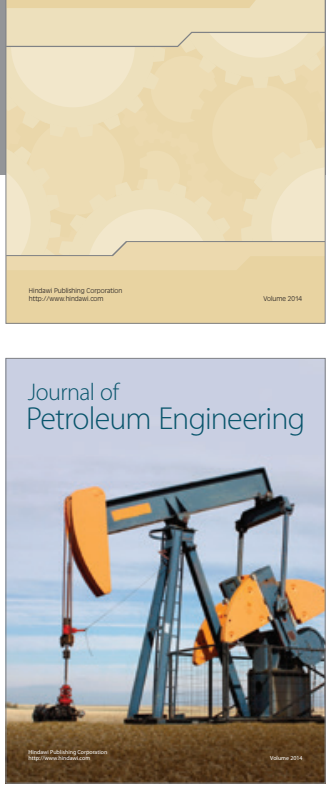

Journal of

Solar Energy
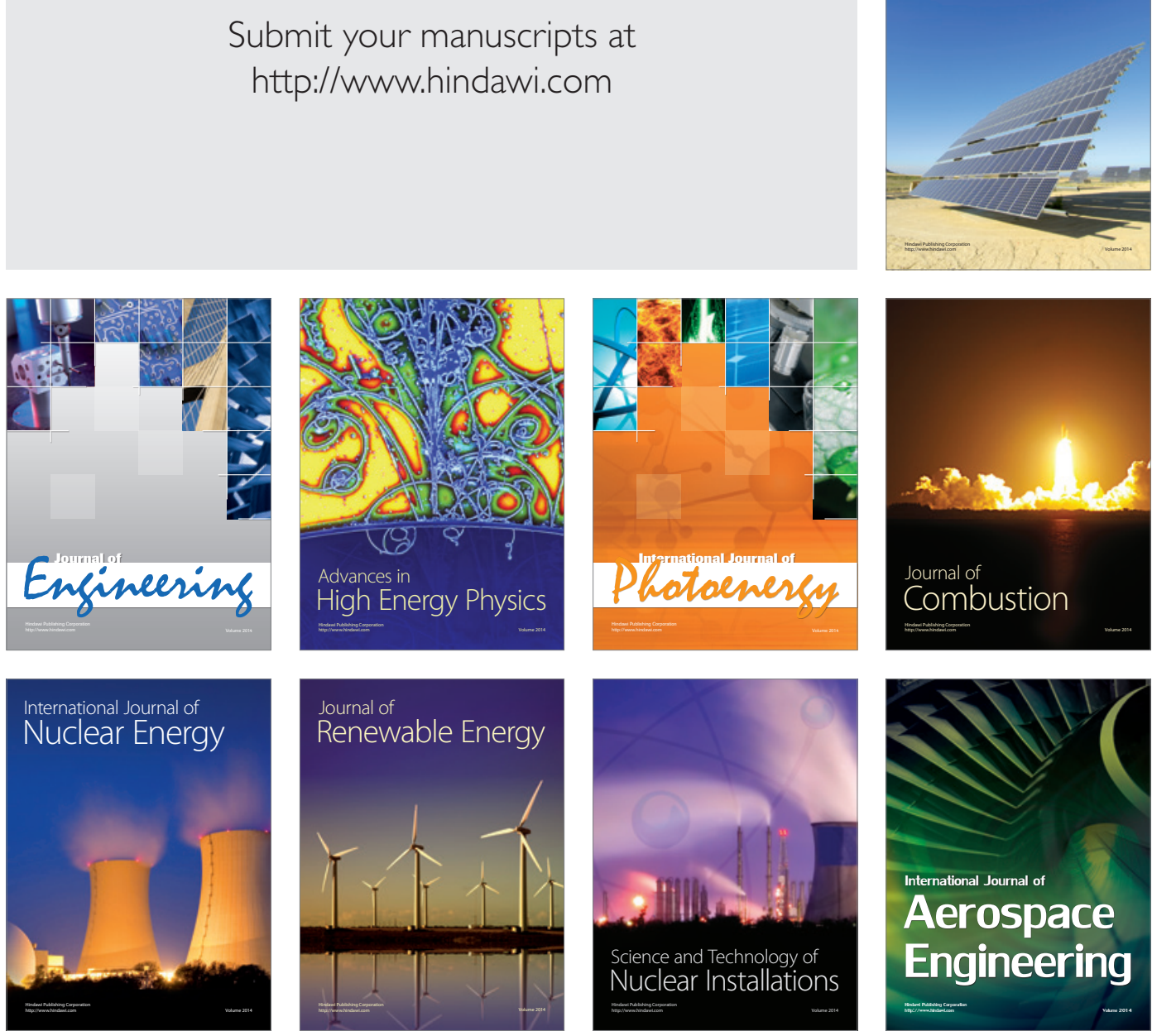